\title{
Integrated reporting in the public sector - case study
}

\section{Abstract}

The paper aims to discuss IR adoption by some public and state-owned entities and identify steps that must be taken by (BKV Zrt.) in the IR implementation process. A fundamental lesson emerging from the case studies is that, as it stands, the IR Framework does not provide sufficient support for public sector entities. Thus, further effort should be made to interpret the peculiarity of public sector organizations. Also, how IR can be applied within Budapesti Közlekedési Zrt. with the expected benefits that may accrue, in addition, the costs that organizations incur in implementing IR must be considered.

Keywords: Integrated reporting (IR), IIRC, state-owned institutions, and public sector

\section{Introduction}

Despite an attempt to improve governmental accounting through financial and non-financial reports, the information and indicators set in the traditional reports are still not sufficient to achieve public accountability (Broadbent-Guthrie 2008; Manes Rossi et al, 2016; Newberry 2015). Recently, new tools for preparing reports with a higher level of accountability have appeared, such as sustainability reports (SR), popular financial reports (PFR), and integrated reports (IR). Although the content of these reports varies, they all aim to improve disclosure in order to meet the stakeholders' needs (CohenKaratzimas 2015). There are few studies that examined the theoretical and practical results of the public and state-owned institutions that have adopted integrated reports by studying different cases to determine whether integrated reports are an appropriate disclosure tool in the public sector and compatible with the needs of stakeholders

1 PhD student at Budapest Business School - Hungary, Teaching assistant at the Faculty of Commerce - Assuit University - Egypt; e-mail: nada.omar@aun.edu.eg

DOI: http://dx.doi.org/10.31570/Prosp 2021_1 4 
as such (Lucia 2018; Manes Rossi 2018; IIRC and CIPFA, 2016). The main purposes of this paper are basically to discuss integrated reporting adoption by some public entities, identify steps that must be taken by Budapesti Közlekedési Zrt. (BKV Zrt.) in the IR implementation process, finally, to present expected benefits and difficulties of IR adopting in Budapesti Közlekedési Zrt. (BKV Zrt.). To achieve that, this paper tries to answer the following main research questions:

- What are the benefits of adopting IR by public and state-owned entities (case studies)?

- What steps must be taken to adopt IR in Budapesti Közlekedési Zrt. (BKV Zrt.)?

- What is the possible utilization of IR adoption in Budapesti Közlekedési Zrt. (BKV Zrt.) and what are possible difficulties in the implementation process?

In the current study, a brief summary of the integrated reports and their role in the public sector will be presented, and then a presentation of some public and owned-state institutions that have adopted integrated reports, which were studied in the literature as case studies. In addition to that, the steps that Budapesti Közlekedési Zrt. (BKV Zrt.) should follow to adopt integrated reports as a main disclosure tool, and a brief presentation of the advantages and obstacles in the implementation process are presented.

\section{Theoretical part}

\section{Literature review}

Debate on IR has received an increased interest from academic scholars, in general and in the public sector as well. More specifically, it is worth mentioning that there are several scholars who have discussed the similarities and differences between the traditional system of reporting and the new forms of reporting such as sustainability reports and integrated reports for instance, Jenes and Berg (2012); Krongkaew-arreyaand Setthasakko (2013). In the same vein, a large and growing body of researchers has investigated and analysed the potential benefits of integrated reporting adoption and has found mixed results. For example, the results of Churet and Eccles' (2014) study, which focused on some sectors, confirmed that there is a positive relationship between IR and financial performance in two sectors; healthcare and information technology, moreover, a positive correlation between effective management of ESG issues and IR. Additionally, Mervelskemper and Streit (2015) found that integrated reporting 
adoption does not enhance the performance of companies that previously issued an independent sustainability report. In another study, Lee and Yeo (2015) summarized that firm valuation is positively associated with IR disclosures, and this association is stronger for firms with higher organizational complexity.

On the other hand, in the public sector academic literature, there have been several studies that presented integrated reporting. For example, the impact of IR adoption in the public sector on sustainability disclosure was examined by Montecalvo et al. (2018) in the New Zealand Post (NZ Post) during the period 2001 to 2015. Results revealed that integrated reporting enhances sustainability disclosure. Another trend of research focused on different types of public accountability methods in the public sector. To give an illustration, Lucia and Enrico (2018) focused on the similarities and differences between integrated reports, sustainability reports and popular reports. A similar study in the same context discussed the future of reporting in the public sector by examining sustainability reports and popular reports and how to link them in order to achieve the interest of all users (Cohen-Karatzimas 2015). A further example is the study of Manes-Rossi (2018); he examined whether integrated reporting is a new challenge in the public sector by presenting a group of local institutions that have adopted integrated reports that differ in terms of legal structures, business models and geographic location. Additionally, IR implementation, truthfulness, and efficiency have been discussed in non-profit and public firms (Oprisor et al. 2016; Biondi-Bracci 2018).

In general, studies on the adoption of integrated reporting by public, state-owned, and non-profit institutions are still not enough (Villiers et al. 2019; Biondi-Bracci 2018). This opens an opportunity for academics to conduct more research, for example, IR applicability, advantages, obstacles, and the impact on the success factors of the public sector and state-owned institutions.

\section{Integrated reporting overview}

As a result of dissatisfaction about the traditional corporate reporting models, the IIRC was formed in 2010 by the Global Reporting Initiative (GRI), "an international, independent body that produces \& makes available the world's most trusted \& widely used standards for sustainability reporting", and the Prince of Wales' Accounting for Sustainability Project (Montecalvo et al. 2018). However, even though IR stemmed from the sustainability movement, the IR framework, published in 2013, subordinates sustainability to value creation (IIRC, 2013). This procedure aims to introduce an integrated reporting that covers the non-financial information in addition to the usual financial 
ones in a manner allowing for an assessment of the ongoing future performance of the company (IIRC, 2013).

According to IIRC (2013), integrated reports can be defined as the process that leads to an integrated periodic report by the organization about value creation as a result of integrated thinking. IR aims to introduce a brief and comprehensive description of the firm's value and its performance by disclosing a comprehensive set of financial, human, intellectual, environmental, and social factors that affect the company's ability in the short, medium, and long term. Hence, IR provides a distinct view of business activities over time to all interested parties.

Capitals, content elements, and guiding principles are the three basic dimensions which are included in the IR Framework to govern the context of the integrated report, these dimensions guide and assist corporations in preparing integrated reports through replacing their annual, sustainability, and any other publicly available corporate reports to non-regulatory stakeholders (IIRC, 2011). Firstly, capitals are the resources and relationships that are used and impacted by enterprises. In more detail, based on the IR Framework, capitals represent stocks of value used as inputs also stocks of value outputted by organizations through their business models. Capitals can be classified into six main types as explained on pages 11-12 of the IR Framework: financial, manufactured, intellectual, human, social and relationship, and natural (IIRC, 2013a, b). Based on the nature of corporations' industries and their needs, they may place different emphases on reporting the various capitals such as comparing disclosures about capitals across different industries. Secondly, content elements present a guide to information included in integrated reports and are linked to each other that are used by enterprises to explain their unique value-creation stories by presenting the connections between these elements. These elements are classified into nine categories as mentioned in the IR Framework: organizational overview and external environment, governance, business model, risks and opportunities, strategy and resource allocation, performance, outlook, the basis of preparation and presentation, and general reporting guidance. Thirdly, guiding principles aim to ensure the quality of integrated reports and to achieve transparency and comparability of the integrated reports amongst different organizations. In the IR Framework seven guiding principles are pointed out. These guiding principles include strategic focus and future orientation, connectivity of information, stakeholder relationships, materiality, conciseness, reliability and completeness, and consistency and comparability.

In the same context, the relevance of integrated reports comes from the importance of disclosed information in these reports. In a broad sense, these reports include 
information on environmental and social aspects, and others related to governance mechanisms, in addition to information related to risks and the procedures taken by the management to reduce them and finally integrated reports extend to include information about the future forecasts and estimates. However significant the relevance of integrated reports is, its adopting comes with several risks and challenges, to give an illustration: one of these challenges and risks are the problems associated with the excessive confusion of information and the inability of users to benefit from it, furthermore, the high cost of disclosure in these reports, this high cost not only includes the preparation and publication of integrated reports, but also the possibility of their negative impact on the competitive and negotiating position of the company. So, the benefits of these reports are limited; this is due to the absence of a binding capacity regarding the disclosure of these reports and the absence of binding accounting standards in this regard. (Adams-Simnett 2011)

\section{IR in public and state-owned organizations}

According to Roper and Schoenberger-Orgad (2011), there are several common characteristics between SOEs as part of the public sector with private sector businesses; both of them are operating competitively, and also the main aim of each one is profits, while Allini et al. (2016) mentioned that SOEs differ from private sector businesses in more details, SOEs often have a requirement to pursue wide-ranging social and environmental goals on behalf of the State; moreover, the OECD Guidelines on Corporate Governance of SOEs (2005: 44) states that these enterprises "should be as transparent as publiclytraded corporations and should disclose financial and non-financial information".

Since the global financial crisis, there have been many challenges that business organizations face in general and public sector institutions in particular. These challenges are due to the lack of resources used in the public sector, the multiple and different activities, in addition to the diversity of stakeholders and the wide definition of the value creation process. Therefore, public, and state-owned institutions are more accountable in order to achieve more transparency to understand the efficiency and effectiveness of these institutions in the value creation process (Greiling 2013). In this regard, public accountability must contain all financial and non-financial information and how public resources are used and transformed into outputs through the value creation process. (Benito et al. 2008; Carini et al, 2018; Manes-Rossi et al. 2018). Despite initiatives taken by International Public Sector Accounting Standards (IPSAS) and European Public Sector Accounting Standards (EPSAS) to improve public accountability, traditional 
financial reports do not provide all the information that stakeholders need (Steccolini 2004).

Therefore, in recent times, there has been an increasing trend in the public sector and state- owned enterprises (SOEs) to prepare different types of reports such as (sustainability report, governance report, human rights report, etc.). These types of reports have a common goal of going beyond traditional financial reporting by providing more useful financial and non-financial information to stakeholders (IIRC and CIPFA, 2016). The process of creating value in the public sector and SOEs is a great story that must be communicated to all stakeholders, as it relies on intangible capital such as social and human resources for positive change in society (Jonathan 2018). Thus, integrated reports represent a good opportunity for the local community, as the integrated report provides an integrated view of the organization's activities and strategies, the extent of utilization of the available resources, opportunities, current and potential risks, and other financial and non-financial information, which benefits the stakeholders about the institution's ability to create value in the short, medium and long term, thus adopting IR contributes to dealing with various and conflicting public accountability (Lucia-Enrico 2018; IIRC and CIPFA, 2016).

\section{Methodology}

For an investigation of how or why some phenomenon's, which the scholar doesn't have control over, case studies are considered a suitable research method (Yin 2014). This study discusses the IR adoption by local community as a new disclosure tool and provides some suggestions to Budapesti Közlekedési Zrt. (BKV Zrt.) for the implementation process. In doing so, a case study approach has been adopted. Case studies are an appropriate research method to present the IR implementation in the public sector and summarize its benefits and difficulties in that sector.

\section{Case Studies}

\section{Auditor-General of South Africa (AGSA)}

Auditor-General of South Africa is considered as one of the state institutions supporting constitutional democracy ${ }^{2}$ and it is responsible for auditing and reporting on the accounts of all national and regional government administrations, in South Africa. The

2 https://www.agsa.co.za/AboutUs/Legislation.aspx 
year 2012 marked the beginning of the AGSA commitment to integrated reports as it published its first integrated report that year, and AGSA was able to achieve benefits from adopting these reports which are the following:

- Integrated reports provide a good framework for accountability based on predefined goals and objectives.

- Focusing on stakeholders by long-term sustainable value creation (CIMA).

- The integrated report provides clear information about the AGSA operating system, and actual and potential risks.

- The report details the main performance indicators and reporting limits that are liable to audit (CIMA).

\section{ENI}

ENI is an Italian state-owned company working in the oil and gas sector. As a result of the nature of its activity, ENI must disclose all of its non-commercial dealings and its environmental and social obligations. ENI abandoned independent sustainability reporting and began adopting integrated reports in 2010 under the program launched by IIRC. The adoption of integrated reports has resulted in many advantages:

- The Chairman and CEO of ENI announced that the shift to integrated reporting has made the decision-making process smoother, as well as saved 770 million euros costs on an annual basis.

- Providing short and long-term forward-looking information.

- Although the integrated report of the company does not provide information on the six capitals specified in the framework of the integrated report, it clarifies peculiar assets in relation to the six dimensions of the value creation process.

- Providing an in-depth audit of the reporting period.

- ENI's integrated approach obligated it to build internal risk control systems on sustainability issues based on stakeholder requirements.

- Defining the company's strategies based on the participation of its employees, shareholders, and the communities in which it operates, such as customers, suppliers, local and international organizations, the financial community, and others (Manes 2018). 


\section{Rosatom}

It is one of the largest state-owned energy generation firms in Russia and one of the major companies in the field of the use of nuclear energy in the world. Rosatom's annual report in 2016 was considered a unique case for preparing the integrated report, as it clearly showed the main business activities and their connection with the six capitals in addition to their use in the value creation process, also, a clear identification of actual and potential risks, the risk management system and linking them to strategic objectives appeared, despite this, Rosatom relied on the limited participation of stakeholders in identifying strategies (CIMA).

\section{The Crown Estate, UK}

The UK Crown Estate is a semi-independent, united public body and its main activity is to manage a real estate portfolio on behalf of the state. The company has begun adopting the integrated approach in its report since 2012, and this was clearly shown in subsequent reports. In the 2013 report, The UK Crown Estate was able to identify the main financial, environmental, or social issues that affect performance. In the 2015 report, it focused on developing effective measurement indicators and clarifying its positive and negative impact on society. The company seeks to develop its IR from year to year, believing that the integrated report positively affect the company, its partners, customers, and stakeholders (CIMA).

\section{NZ Post Group, New Zealand}

The New Zealand Post Group operates as a state-owned enterprise and provides its postal services through a group of stores. In order to be successful in evaluating its capitals, in 2013 it began to use integrated reporting as an approach that helps it in strategic thinking to create value. The 2014 report was divided into six major capitals: Relationship, Networks, Expertise, People, Environment and Finances. Benefits of $<\mathrm{IR}>$ as articulated by NZ Post include:

- Highlighting the interconnections across the business

- Providing a simplified, coherent view of the business

- Improving the understanding of the value of non-financial assets

- Facilitating a longer-term view of the business

- A stronger focus on material issues

- Renewed emphasis on stakeholder engagement

- Greater internal ownership of the report; and even

- A shorter more accessible report (CIMA) 


\section{NHS Greenwich Clinical Commissioning Group (GCCG), UK}

It is a governmental organization responsible for providing health services to people in Greenwich. The first integrated report issued by the organization came out in 2013, in which it detailed:

- The organization's strategies and governance structures that contribute to creating value at the short, medium, and long terms

- The management approaches in the GCCG to identify its stakeholders clearly to have the full confidence in their management way.

- The business model, key inputs, priorities, and activities that contribute to reaching the targeted results. (CIMA)

\section{Munich airport}

It is a governmental organization owned by the state, which started issuing integrated reports in 2010, and since that time it has become a member of the $<\mathrm{IR}>$ Business Network. The integrated report was prepared according to IIRC principles, but at the same time it adhered to international and German reporting standards. The integrated report explained in detail:

- Long- and short-term strategies and key activities that contribute to creating value.

- Current and anticipated risks, risk management system, and the financial and non-financial impact of these risks, as well as the same for future opportunities.

- Based on the needs of internal and external stakeholders which have been clearly identified, all information deemed essential to them is presented in relation to the six capitals (financial, infrastructure, expertise, employees, environment, and society).

- The company provides an annual report, an integrated report, and a sustainability report, but the integrated report provides all the information needed to understand the company's business model and the value creation process.

- The report also demonstrates that the company's relationship with its stakeholders is pivotal and it is strengthened through the company's website, social networks, surveys, meetings, and work groups (Manes 2018). 


\section{Summary and discussion of case studies}

The following Table provides a comparative presentation of the analyzed cases based on the availability of the integrated reporting principles in their reports.

Table 1: A comparative presentation of the analyzed cases based on the availability of the integrated reporting principles in their reports

\begin{tabular}{|c|c|c|c|c|c|c|c|}
\hline & 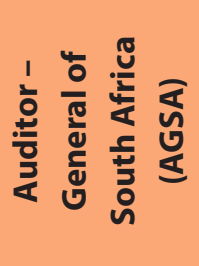 & $\overline{\mathbf{u}}$ & 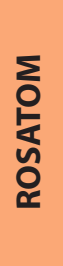 & 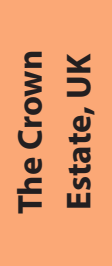 & 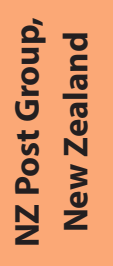 & 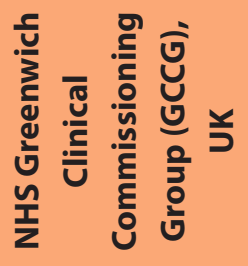 & 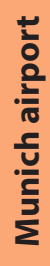 \\
\hline $\begin{array}{l}\text { Strategic focus and } \\
\text { future orientation } \\
\text { (organization's strategy, } \\
\text { and its ability to create } \\
\text { value in the short, } \\
\text { medium, and long term) }\end{array}$ & $\sqrt{ }$ & $\sqrt{ }$ & $\sqrt{ }$ & $\sqrt{ }$ & $\sqrt{ }$ & $\sqrt{ }$ & $\sqrt{ }$ \\
\hline $\begin{array}{l}\text { Connectivity } \\
\text { of information }\end{array}$ & $\sqrt{ }$ & $\sqrt{ }$ & $\sqrt{ }$ & $\sqrt{ }$ & $\sqrt{ }$ & $\sqrt{ }$ & $\sqrt{ }$ \\
\hline $\begin{array}{l}\text { Stakeholders' } \\
\text { relationships }\end{array}$ & - & $\sqrt{ }$ & $\mathbf{x}$ & $\sqrt{ }$ & $\sqrt{ }$ & $\sqrt{ }$ & $\sqrt{ }$ \\
\hline $\begin{array}{l}\text { Materality } \\
\text { (disclose information } \\
\text { about matters that } \\
\text { substantively affect the } \\
\text { organization's ability } \\
\text { to create value) }\end{array}$ & $\sqrt{ }$ & $\sqrt{ }$ & $\sqrt{ }$ & $\sqrt{ }$ & $\sqrt{ }$ & $\sqrt{ }$ & $\sqrt{ }$ \\
\hline $\begin{array}{l}\text { Conciseness } \\
\text { (sufficient context } \\
\text { to understand the } \\
\text { organization's strategy, } \\
\text { without being } \\
\text { burdened with less } \\
\text { relevant information) }\end{array}$ & - & $\sqrt{ }$ & $\sqrt{ }$ & - & $\sqrt{ }$ & $\mathbf{x}$ & $\sqrt{ }$ \\
\hline Cost savings & - & $\sqrt{ }$ & - & - & - & - & - \\
\hline
\end{tabular}


Based on the analysis of selected cases from public and state-owned institutions that have adopted integrated reports to varying degrees, the essence of integrated reports lies in communicating the value-creating process within these institutions and how to convert inputs into outputs and final results according to the requirements of different groups of stakeholders. By reviewing previous studies that analyzed these cases, it can be said that ENI, NZ Post Group, NHS Greenwich Clinical Commissioning Group (GCCG), UK and Munich Airport prepared their integrated reports in light of the IR guideline principles, also ENI achieved cost savings of 770 million euros with the adoption of integrated reports. Although Rosatom has relied on guiding principles when preparing integrated reports, the level of stakeholder participation in preparing its reports is quite low. Regarding the Auditor-General of South Africa (AGSA) and The Crown Estate UK institutions, they adopted integrated reports, but there was not enough information in previous studies regarding the extent of stakeholder participation in preparing AGSA reports and to what extent the Conciseness principle was achieved in both reports.

\section{IR adoption steps in Budapesti Közlekedési Zrt. (BKV Zrt.)}

BKV, the Budapest Transport Company was established in 1968, it is held by the Municipality of Budapest, runs most of the vehicles (bus, tram, metro, and trolleybus) of the extensive network of public transportation in Budapest. 3

There are three main steps for implementing integrated reports, but before listing these steps, organizations must make their decision to adopt integrated reports and be aware of the comprehensive framework provided by these reports. In addition, the decision to adopt integrated reports must be supported by all departments, divisions, and branches because the implementation process requires breaking down barriers and agreeing on how to use the capitals to create value (IIRC and CIPFA, 2016). It should also be borne in mind that adopting these reports does not mean that they will cancel other reports. IR will become the firm reporting norm to provide an integrated picture of the organizations' activities. Other forms of reporting can be used to communicate specific and detailed information to stakeholders. The steps that must be followed by BKV Zrt to adopt IR are as follows:

3 https://www.bkv.hu/ 


\section{Stakeholder identification}

Questions to be answered in this step: "Who they are? What are their current and future expectations of Budapesti Közlekedési Zrt. (BKV Zrt.)? And, to what extent does BKV Zrt. strategy or business model need to be amended to reflect these expectations?"

It is necessary to identify the main stakeholders, understand and study their current and future expectations, and accordingly determine the rate of adjustments to be made in the organization's strategy and business model to reflect the needs of stakeholders (CIMA). Stakeholder identification is beneficial to the organization in many ways, such as identifying current and future opportunities and risks, developing strategies, and defining the material issues that are reported in the integrated report (IIRC and CIPFA, 2016).

\section{Allocation of the resources required to implement these changes}

Questions to be answered in this step: "Are the different parts of (BKV Zrt.) talking to each other to achieve the delivery of a coherent strategy? And what more can (BKV Zrt.) do?"

\section{Relocate the new strategy clearly and concisely}

Here it is necessary to determine the effect of implementing the strategy that was prepared based on the needs of the various stakeholders in the operating environment at Budapesti Közlekedési Zrt. (BKV Zrt.).

\section{The possible benefits and difficulties of IR adoption}

There are a wide range of outcomes and positive impacts behind adopting integrated reports in the public sector and SOEs. These benefits have been established from more than 60 organizations implementing $<\mathrm{IR}>$ by the managers and leaders of these sectors, and these outcomes may be potential benefits for adopting IR in Budapesti Közlekedési Zrt. (BKV Zrt.) (IIRC \&CIPFA, 2016). Theses impacts can be summarized as follows:

I. IR adoption enhances the issues of performance understanding and public value creation at both leadership and employee levels through clear objectives and related metrics and identifying the relationship between these key financial and 
non-financial metrics, in addition to growing the external stakeholder base and supporting accountability.

II. IR adoption improves the process of decision-making to deliver sustainable outcomes through developing a set of metrics to ensure that the strategies, objectives, and activities coincide with the mission and vision of the organization because it - IR - has the potential to improve the management information.

III. In terms of stakeholders, IR assists all interested parties such as; employees, customers, suppliers, business partners, local communities, municipal councils, legislature (or similar body), members of parliament (or a similar representative body), regulators and policymakers, in evaluating the organization's ability to create value over time, moreover IR provides insight into the nature and quality of the organization's relationships with its key stakeholders, including how and to what extent the organization understands, takes into account and responds to their legitimate needs and interests, further more IR allows stakeholder engagement that may result in helping the organization to show how it balances the often- conflicting needs of different stakeholder groups (KPMG, 2012).

IV. IR has certain qualities and strengths such as its ability to take account of multiple inputs of different kinds and its focus on long term value creation and its appreciation of the importance of non-financial value, IR supports public entities in addressing their challenges and it also addresses the diverse, and often conflicting public accountability requirements.

V. Scholars and standard setters concluded that IR adoption in public sector entities plays a fundamental role in public entities, it also may enhance democratic participation and increase citizens 'trust (IIRC and CIPFA, 2016; Katsikas et al. 2017).

VI. IR leads to better disclosure that improves trust within the entity, and integrated thinking reduces the risk of weak coordination, thus enhancing synergy and favouring the identification of key drivers of public value creation, in other words, IR supports the disclosure to ensure greater clarity regarding relationships and commitment (Eccles-Krzus 2010).

On the other hand, integrated report adoption has some limitations and risks, for example it requires unifying the values and strategies of managers and officials within the organizations, and this is a little complicated (Katsikas et al. 2017), in addition to that it may lead to a superficial change in management procedures or in the form of reports and not a fundamental one. (Liguori-Steccolini 2014). Moreover, the lack of perfor- 
mance indicators for integrated reports opens the way to choosing different criteria and indicators for each entity, which makes it difficult to make comparisons (Manes Rossi 2018).

\section{Final remarks}

Debate on IR has received increased interest from professionals, organizations, standard setters, and scholars in both the private and public sectors. More specifically, early adopters effectively contribute to the improved definition the content and approach of which should be followed to ensure the report reflects an innovative way to manage an entity. By analysing different case studies, this study makes it possible to consider how the approach to IR has been interpreted in different contexts and how stakeholders may be involved in defining material issues. However, it does not investigate internal processes and, consequently, does not allow for an assessment of whether integrated thinking permeates the various organizations. A fundamental lesson emerging from the case studies is that, as it stands, the $<\mathrm{IR}>$ Framework does not provide sufficient support for the public sector and state-owned entities for it to be considered the primary reference for accountability purposes. Thus, further effort should be made to interpret the peculiarity of public sector organizations. Also, the costs that organizations incur in implementing IR, whether material or immaterial, must be taken into account. We can say that stakeholder engagement is a key aspect of the accountability process. IR, then, maybe considered a tool to enhance stakeholder engagement, improve accountability, and, in turn, gain legitimacy (Beck et al. 2017; Guthrie et al. 2017). Standard setters are aware of the relevance of this new tool and are working to provide better support for IR preparation, thus further research on public sector entities would be beneficial, as it would enable a better understanding of how they create public value for the benefit of the community. So, through working collaboratively with these standard setters, scholars can contribute to discussions about IR content, principles, and practices, and it is necessary to do their best to avoid the rhetorical use of this tool and unveil all the management changes that are necessary for the implementation of reliable reports that address stakeholders' information needs. 


\section{References}

Adams, S. - Simnett, R. (2011). Integrated reporting: an opportunity for Australia's not-for-profit sector. Australian Accounting Review, 21(3), 292-301. https://doi. org/10.1111/j.1835-2561.2011.00143.x

Allini, A. - Manes Rossi, F. - Hussainey K. (2016). The board's role in risk disclosure: an exploratory study of Italian listed state-owned enterprises. Public Money \& Management, 36(2), 113-120, https://doi.org/10.1080/09540962.2016.1118935

Benito, B. - Montesinos, V. - Bastida, F. (2008). An example of creative accounting in public sector: The private financing of infrastructures in Spain. Crit. Perspect. Account, 19(7), 963-986. https://doi.org/10.1016/j.cpa.2007.08.002

Broadbent, J. - Guthrie, J. (2008). Public sector to public services: 20 years of "contextual" accounting research. Account. Audit. Account. J., 21(2), 129-169. https://doi. org/10.1108/09513570810854383

Biondi, L. - Bracci, E. (2018). Sustainability, popular and integrated reporting in the public sector: A fad and fashion perspective. Sustainability, 10(9), 3112. https://doi. org/10.3390/su10093112

Carini, C. - Rocca, L. - Veneziani, M. - Teodori, C. (2018). Ex-ante impact assessment of sustainability information-the directive 2014/95. Sustainability, 10(2), 560. https://doi.org/10.3390/su10020560

Cohen, S. - Karatzimas, S. (2015). Tracing the future of reporting in the public sector: Introducing integrated popular reporting. International Journal of Public Sector Management, 28(6): 449-460. https://doi.org/10.2139/ssrn.2524807

Churet, C. - Eccles, R. G. (2014). Integrated reporting, quality of management and financial performance. Journal of Applied Corporate Finance, 26(1), 56-64.

Eccles, R. G. - Krzus, M. P. (2010). One Report. Integrated reporting for a sustainable society. 207-227, USA. https://doi.org/10.1002/9781119199960.ch8

Greiling, D. - Halachmi, A. (2013). Accountability and organizational learning in the public sector. Public Perform. Manag. Rev., 36(3), 380-406. https://doi.org/10.2753/ pmr1530-9576360301

Hyndman, N. - Lapsley, I. (2016). New public management: The story continues. Financial Accountability \& Management, 32(4), 385-408. https://doi.org/10.1111/ faam. 12100

International Integrated Reporting Council, (IIRC) (2013). The International Integrated Reporting Framework. London: International Integrated Reporting Committee, IIRC. 
International Integrated Reporting Council (IIRC) and CIPFA (2016). Focusing on value creation in the public sector. https://integratedreporting.org/resource/focusing-on-value-creation-in-the-public-sector/

Jensen, J. C. - Berg, N. (2012). Determinants of traditional sustainability reporting versus integrated reporting. An institutionalist approach. Business Strategy and the Environment, 21(5), 299-316. https://doi.org/10.1002/bse.740

Jonathan, L. (2018). Why public bodies are adopting integrated reporting. Available at: https://www.publicfinancefocus.org/opinion/2018/10/why-public-bodies-areadopting-integrated-reporting1

Katsikas, E. -, Manes-Rossi, F. - Orelli, R. (2017). Towards Integrated Reporting - Accounting Change in the Public Sector. Springer, Switzerland, Integrated Reporting, 191-204. https://doi.org/10.1007/978-3-319-02168-3 12

KPMG (2012). Applying Integrated Reporting principles in the public sector, retrieved 11. December, 2017. From https://home.kpmg.com/content/dam/kpmg/ pdf/2013/04/applyingir- principles.pdf

Krongkaew-arreya, N. - Setthasakko, W. (2013). Influence factors to develop sustainability report: A case study of Thailand. London: Proceedings of 8th Annual London Business Research Conference, 1-11.

Liguori M. - Steccolini, I. (2014). Accounting, innovation and public sector change. Translating reforms into change? Critical Perspectives on Accounting, 25(4-5), 319323. https://doi.org/10.1016/j.cpa.2013.05.001

Lucia, B. - Enrico, B. (2018). Sustainability, Popular and integrated reporting in the public sector: A fad and fashion perspective. Sustainability, 10(9), 3112. https://doi. org/10.3390/su10093112

Manes Rossi, F. - Cohen, S. - Caperchione, E. - Brusca, I. (2016) . Harmonizing public sector accounting in Europe: Thinking out of the box. Public Money Manag., 36(3), 189-196. https://doi.org/10.1080/09540962.2016.1133976

Manes-Rossi, F. - Tiron-Tudor, A. - Nicolò, G. - Zanellato, G. (2018). Ensuring more sustainable reporting in Europe using non-financial disclosure-de facto and de jure evidence. Sustainability, 10(4), 1162. https://doi.org/10.3390/su10041162

Manes Rossi, F. (2018). Is integrated reporting a new challenge for public sector entities? African Journal of Business Management, 12(7), 172-187. https://doi.org/10.5897/ ajbm2018.8498

Mervelskemper, L. - Streit, D. (2015). Investors' perception of ESG performance: Is integrated reporting keeping its Promise? SSRN Electronic Journal, https://doi. org/10.2139/ssrn.2625044 
Montecalvo, M. - Farneti, F. - De Villiers, C. (2018). The potential of integrated reporting to enhance sustainability reporting in the public sector. Public Money \& Management, 38(5), 365-374. https://doi.org/10.1080/09540962.2018.1477675

Newberry, S. (2015). Public sector accounting: Shifting concepts of accountability. Public Money \& Management, 35(5), 371-376. https://doi.org/10.1080/09540962.2015.106 $\underline{1180}$

Oprisor, T. - Tiron-Tudor, A. - Nistor, C. S. (2016). The integrated reporting system: A new accountability enhancement tool for public sector entities. Audit Financiar, 14(139), 749-762. https://doi.org/10.20869/auditf/2016/14/747

Roper, J. - Schoenberger-Orgad, M. (2011). State-owned enterprises; Issues of accountability and legitimacy. Management Communication Quarterly, 25(4), 693-709. https:// doi.org/10.1177/0893318911415598

Schillemans, T, (2016). Calibrating public sector accountability. Translating experimental findings to public sector accountability. Public Management Review., 18(9), 14001420. https://doi.org/10.1080/14719037.2015.1112423

Steccolini, I. (2004). Is the annual report an accountability medium? An empirical investigation into Italian local governments. Financial Accountability and Management, 20(3), 327-350. https://doi.org/10.1111/j.0267-4424.2004.00389.x

Yin, R. K. (2014). Case Study Research: Design and Methods. 5th ed. Sage, Thousand Oaks, CA. https://doi.org/10.3138/cjpe.30.1.108

Villiers, Ch. - Rinaldi, L. - Unerman, J. (2019). Integrated reporting: Insights, gaps and an agenda for future research. Accounting, Auditing and Accountability Journal, 27(7), 1042-1067. https://doi.org/10.1108/aaaj-06-2014-1736 